\title{
VIABILIDADE DAS SEMENTES DE SERINGUEIRA EM FUNÇÃO DO TEMPO DE ARMAZENAMENTO
}

\author{
VIABILITY OF RUBBER TREE SEEDS AS A FUNCTION OF STORAGE TIME
}

\author{
Lucas Antonio de Souza Cassiano Dutra ${ }^{1}$, Joseanny Cardoso da Silva Pereira ${ }^{2 *}$, Sara Raquel Mendonça ${ }^{3}$ \\ ${ }^{1}$ Graduando em Agronomia pela Faculdade Evangélica de Goianésia. \\ ${ }^{2}$ Agrônoma, Mestre em Produção Vegetal, Doutora em Agronomia, Professora Adjunta na Faculdade Evangélica de \\ Goianésia. E-mail: profjoseanny@gmail.com \\ ${ }^{3}$ Agrônoma, Mestranda em Produção Vegetal pela Universidade Federal de Goiás
}

\section{Info}

Recebido: 01/2019

Publicado: 06/2019

ISSN: 2595-6906

\section{Palavras-Chave \\ Hevea brasiliensis L. Tetrazólio. Condutividade elétrica}

Keywords:

Hevea brasiliensis L. Tetrazolium. Electric conductivity.

\section{Resumo}

As sementes de seringueira possuem alta taxa de perecimento por serem recalcitrantes, o que dificulta o seu armazenamento. Além disso, a constatação da viabilidade da semente normalmente ocorre pelo teste de emergência de plântulas em canteiro, o qual varia dos 10 aos 30 dias, período em que a viabilidade da semente pode cair significativamente. Dessa forma, a utilização de testes rápidos que verifiquem a viabilidade das sementes antes do plantio é essencial para fornecer informações sobre seu poder germinativo. Dentre eles, pode-se citar o teste de condutividade elétrica, de umidade e de tetrazólio. Assim, objetivou-se analisar a viabilidade de sementes de seringueira do clone RRIM600 em função do tempo de armazenamento. Coletou-se 4 mil sementes de seringueira do clone RRIM 600, as quais foram colocadas em sacos plásticos, lacrados em seguida e armazenados à temperatura ambiente $\left( \pm 26^{\circ} \mathrm{C}\right)$. Os testes (emergência de plântulas em canteiro de areia, tetrazólio, umidade, condutividade elétrica) foram realizados no dia da coleta e depois aos 30, 60 e 90 dias após o armazenamento. 0 experimento foi conduzido em delineamento inteiramente casualizado com quatro tratamentos (armazenados por 30, $60 \mathrm{e}$ 90 dias) e quatro repetições. Não houve diferenças significativas entre as médias de porcentagem do teste de emergência de plântulas em canteiro e da estimativa de germinação do teste de tetrazólio. Houve correlação positiva entre porcentagem de germinação e a estimativa obtida pelo teste de tetrazólio ao longo do período de armazenamento, correlação negativa entre a porcentagem de emergência de plântulas e o teor de umidade e a condutividade elétrica. A análise de regressão da porcentagem de emergência de plântulas de seringueira em função do tempo de armazenamento gerou modelo quadrático com valores de R2 significativos a 5\% de probabilidade. Com relação ao teor de umidade em função do tempo de armazenamento, obteve-se modelo linear, com R2 significativo a 5\% de probabilidade. Dessa forma, conclui-se que o teste de tetrazólio pode ser utilizado em substituição ao teste de emergência de plântulas em canteiro para sementes de seringueira. Os testes de tetrazólio, umidade, e condutividade elétrica são testes eficientes e rápidos na execução. As sementes de seringueira podem ser conservadas viáveis em temperatura ambiente (24-28으) por até 2 meses. A taxa de umidade de aproximadamente $25 \%$ foi a mais eficiente para a conservação das sementes de seringueira. 


\section{INTRODUÇÃO}

O cultivo da seringueira é realizado com a finalidade de extração do látex que é utilizado na fabricação de mais de 50 mil itens oriundos desta matéria-prima (BONOME, 2006; NOGUEIRA et al., 2015). Entre eles, pode-se citar os pneus de automóveis originários da vulcanização desenvolvida por Charles Goodyear (D’AGOSTINI et al., 2013), câmaras de ar para pneus, luvas cirúrgicas, balões, dentre outros mais, e que estão presentes nas nossas vidas como objetos de grande importância.

O Brasil produziu 183 mil toneladas de borracha em 2017 (TOLEDO, 2018). Os maiores estados produtores são: São Paulo, Bahia, Mato Grosso, Minas Gerais, Goiás, e Espírito Santo (ABRABOR, 2014). É importante destacar que em 2016, Goiás possuía a maior média de produção mundial por hectare, sendo $1,53 \mathrm{t} \mathrm{ha}^{-1}$ e dentre os principais municípios produtores em Goiás está a região de Goianésia (PICHELLI, 2016).

A formação dos seringais ocorre por meio de mudas, as quais são produzidas por enxertia e os portas-enxertos são obtidos via sementes (MOREIRA, 2009). As sementes de seringueira possuem alta taxa de perecimento por serem recalcitrantes, o que dificulta o processo de implantação de viveiros para a produção de seringais em épocas de escape, isto é, épocas em que não ocorre o mal-das-folhas. Esta doença é causada pelo fungo Microcyclus ulei (Henn.) Arx. que ocorre nas folhas e se espalha entre as mudas causando a abscisão foliar (FURTADO et al., 2015).
O fungo M. ulei necessita de temperatura e umidade mais alta para se desenvolver, e a época propícia situa-se entre os meses de janeiro a março (FURTADO et al., 2015), desta forma, o armazenamento de sementes é necessário para evitar problemas, como o mau-das-folhas. A possibilidade de armazenar as sementes por mais tempo, ajudará o produtor na mão de obra e diminuirá o espaço de plantio e os custos de implantação (PEREIRA,1980), além de evitar os períodos de temperaturas mais amenas, as quais são prejudiciais à germinação e à conservação da semente de seringueira, que necessita de faixas de temperatura de $23^{\circ} \mathrm{C}$ a $27^{\circ} \mathrm{C}$ para ser armazenada ( PEREIRA, 1980; BONOME et al., 2009).

A semente da seringueira necessita de alta porcentagem de água para ser armazenada (mínimo de 30\%) (PEREIRA, 1980; VIEIRA, BERGAMASCHI, MINOHARA; 1995; BONOME et al., 2009). Por outro lado, essa mesma porcentagem de umidade na semente pode ocasionar o ataque de fungos que penetram na semente junto com a água absorvida e se alimentam de aminoácidos e açúcares nos protoplastos celulares. Esta ação dos fungos resulta em aumento de atividade de degradação dentro da semente (BONOME, 2006).

A germinação da semente de seringueira varia dos 10 aos 30 dias (VIEIRA, 1995; GARCIA, VIEIRA, 1994). Dessa forma, a utilização de testes rápidos que verifiquem a viabilidade das sementes antes do plantio é essencial para fornecer informações sobre seu poder germinativo. Dentre eles, pode-se citar o teste de condutividade elétrica, o teste de umidade e o teste de tetrazólio. 
O teste de condutividade elétrica quantifica os íons lixiviados pela semente na solução de embebição; quanto menor a integridade das membranas, maior a quantidade de íons lixiviados (VIDIGAL et al., 2008). Dessa forma, altos valores de condutividade elétrica revelam a baixa viabilidade das sementes.

Testes de umidade também podem mostrar resultados sobre a germinabilidade da semente de seringueira. Diferente das sementes ortodoxas, que toleram dessecação com perdas de água entre $2 \%$ e 5\% (BONOME, 2009), a semente da seringueira é recalcitrante, isto é, não completa o seu amadurecimento (BARBEDO, CENTENO, RIBEIRO; 2013), sua atividade continua mesmo estando armazenada, pois não tolera dessecações com valores abaixo dos $20 \%$, sendo que a água na semente é fundamental para a integridade estrutural intracelular da semente (BONOME, 2009). A perda de água dentro da semente pode confirmar a diminuição do seu metabolismo, já que sementes com características recalcitrantes perdem viabilidade com a redução do teor de água (BONOME, 2009).

O teste de tetrazólio é uma opção rápida na determinação da viabilidade de sementes de seringueira, pois leva, aproximadamente, $12 \mathrm{~h}$ para obtenção dos resultados (RAS, 2008). Dessa forma, objetivou-se analisar a viabilidade de sementes de seringueira do clone RRIM600 em função do tempo de armazenamento.

\section{MATERIAL E MÉTODOS}

O experimento foi realizado no laboratório de solos da Faculdade Evangélica De Goianésia e na igreja Comunidade Alcance De Goianésia, localizado a cerca de $2 \mathrm{~km}$ do laboratório, que cedeu o espaço de armazenamento e local de testes de emergência de plântulas em canteiro, ambos situados na cidade de Goianésia - Goiás.

\section{Aquisição das sementes}

As sementes de seringueira foram colhidas no seringal da fazenda Fios, no distrito de Goianésia-Goiás no dia 25/02/2018 e transportadas para, então, serem armazenadas. As sementes foram coletadas manualmente, no solo, selecionadas visivelmente por boa aparência e coloração forte e avermelhada, e colocadas em saco de ráfia. Após o transporte das sementes para o laboratório, o trabalho foi iniciado.

Foram coletadas 4000 sementes de seringueira do clone RRIM 600, e colocadas em sacos plásticos de dimensões $30 \times 45 \mathrm{~cm}$ perfurados com um orifício de 1,5 $\mathrm{mm}$ totalizando oito orifícios em cada saco e com 344 sementes por saco. Estes foram lacrados e armazenados à temperatura ambiente em um cômodo de dimensões 3 x 4 m, limpo, revestido com azulejo e arejado, com temperatura ambiente de $\pm 26^{\circ} \mathrm{C}$.

Os testes foram realizados no dia da coleta e depois aos 30, 60 e 90 dias após o armazenamento. O experimento foi conduzido em delineamento inteiramente casualizado com quatro tratamentos (armazenados por 30, 60 e 90 dias) e quatro repetições. Todos os testes realizados são descritos a seguir.

\section{Condutividade elétrica}

Foram utilizados quatro béqueres de 500 $\mathrm{ml}$ contendo $200 \mathrm{ml}$ de água destilada em cada. A 
condutividade elétrica da água destilada contida em cada béquer foi medida com um condutivímetro portátil - Q795P. Em seguida, acrescentou-se 10 sementes em cada béquer, os quais foram colocados de repouso por 24 horas em estufa a temperatura de $25^{\circ} \mathrm{C}$. Após o tempo determinado, a condutividade elétrica da água foi mensurada novamente.

\section{Teste de umidade}

O procedimento foi realizado com 20 sementes. Utilizou-se 20 recipientes de alumínio com tampa, os quais foram lavados com água destilada, e colocados para secagem em forno a $105^{\circ} \mathrm{C}$ durante 30 minutos. Em seguida, foram pesados em balança de $0,1 \mathrm{~g}$ sem conteúdo, depois, adicionou-se semente cortada em pedaços com casca e os recipientes foram novamente pesados. Os vinte recipientes foram colocados novamente no forno a $103^{\circ} \mathrm{C} \pm 1^{\circ} \mathrm{C}$ com as sementes durante 17 horas. Após esse período, os 20 frascos foram pesados novamente em balança de $0,1 \mathrm{~g}$.

\section{Teste de tetrazólio}

Para o teste de tetrazólio, retirou-se a casca da semente. Estas foram colocadas em papeltoalha formando camadas com 25 sementes, e umedecidas. Em seguida, foram colocadas na $\mathrm{BOD}$ à temperatura de $25^{\circ} \mathrm{C}$ por um período de 6 horas.

Após esse período, as sementes foram retiradas da BOD e cortadas longitudinalmente para exposição do embrião e dos cotilédones. Em seguida, as sementes foram colocadas na solução de tetrazólio $0,5 \%$ em copos descartáveis por 3 horas em estufa a $40^{\circ} \mathrm{C}$. Com o período em estufa finalizado, as 200 sementes foram lavadas em água destilada e a viabilidade do embrião da semente foi avaliada com base na tonalidade da coloração (WETZEL et al.,1992). Foram consideradas sementes inviáveis ou não germináveis aquelas com embrião e cotilédone descolorido e as partes coloridas em rosa ou avermelhado, as partes viáveis da semente (OLIVEIRA, MARTINS, NAKAGAWA; 2009), e a semente era considerada viável apenas quando apresentavam o embrião colorido em contado com a parte do cotilédone também colorido.

\section{Teste de emergência de plântulas em canteiro}

Fez-se um canteiro de areia com base em Silva e Ozanan (1989). O canteiro possuía dimensões de $1,80 \times 3,40 \mathrm{~m}$, cercado com tijolos, forrado com uma lona perfurada a fim de ter controle sobre plantas invasoras. A área do canteiro foi dividida em oito blocos de 85 x $90 \mathrm{~cm}$ com fitas para dividir as parcelas de plantio contendo 50 sementes por bloco para cada período de armazenamento, totalizando 400 sementes. As sementes foram semeadas espaçadas $7 \mathrm{~cm}$ e irrigadas diariamente de forma a manter o canteiro sempre úmido.

\section{Análise dos dados}

O experimento foi conduzido em Delineamento Inteiramente Casualizado com o uso de quatro períodos de armazenamento e quatro repetições. Os dados de emergência de plântulas em canteiro e estimativa do teste de tetrazólio não apresentaram normalidade, dessa forma, utilizou-se o teste de Kruskal-Wallis a 5\% de probabilidade. Fez-se também o teste de 
correlação e análise de regressão. Para este último, os dados foram transformados e, assim, apresentaram normalidade.

\section{RESULTADOS E DISCUSSÃO}

Observou-se que não houve diferenças significativas entre as médias de porcentagem do teste de emergência de plântulas e da estimativa de germinação do teste de tetrazólio (Tabela 1). Dessa forma, a utilização do teste de tetrazólio, cujos resultados são obtidos $9 \mathrm{~h}$ após a sua realização, são confiáveis em relação ao teste de emergência de plântulas em canteiro. Portanto, é possível obter informações de determinado lote de sementes de seringueira por meio, somente, do teste de tetrazólio, sem a necessidade da realização do teste de emergência de plântulas, já que os resultados deste último demoram de 7 a 20 dias para obtenção.

Tabela 1 - Emergência de plântulas e estimativa do teste de tetrazólio em sementes de seringueira (Hevea brasiliensis L.) após armazenamento.

\begin{tabular}{lc}
\hline \multicolumn{1}{c}{ Testes } & Emergência de plântulas (\%) \\
\hline Emergência de plântulas - 0 dias de armazenamento & $46 \mathrm{ABC}$ \\
Emergência de plântulas - 30 dias de armazenamento & $58 \mathrm{BC}$ \\
Emergência de plântulas - 60 dias de armazenamento & $43 \mathrm{ABC}$ \\
Emergência de plântulas - 90 dias de armazenamento & $4 \mathrm{~A}$ \\
Tetrazólio - 0 dias de armazenamento & $68 \mathrm{C}$ \\
Tetrazólio - 30 dias de armazenamento & $46 \mathrm{ABC}$ \\
Tetrazólio - 60 dias de armazenamento & $43 \mathrm{ABC}$ \\
Tetrazólio - 90 dias de armazenamento & $20 \mathrm{AB}$ \\
\hline
\end{tabular}

Médias seguidas pela mesma letra não diferem entre si pelo teste de Kruskal-Wallis. Fonte: o próprio autor

O teste de tetrazólio leva em consideração a atividade das enzimas desidrogenases, as quais são essenciais ao processo de respiração da semente. Se o tecido da semente estiver vivo, ocorre a hidrogenação do 2, 3, 5 cloreto de trifenil de tetrazólio e produção do trifenil formazan, que é uma substância vermelha. Dessa forma, é possível distinguir partes vivas, coloridas de vermelho, de partes mortas, não coloridas ou excessivamente coloridas (WETZEL et al., 1992), o que possibilita estimar se a semente tem possibilidade de germinar ou não.

Verificou-se correlação positiva entre porcentagem de emergência de plântulas e a estimativa obtida pelo teste de tetrazólio (Tabela 2) ao longo do período de armazenamento. A porcentagem de emergência de plântulas correlacionou-se negativamente com o teor de umidade e com a condutividade elétrica.

À medida que as sementes são armazenadas, o nível de condutividade elétrica tende a aumentar. Este acontecimento se dá pelo fato de ocorrer danos celulares durante $\mathrm{o}$ armazenamento, isto é, perda de permeabilidade e degradação das membranas da semente (BONOME et al., 2009). 
Tabela 2 - Correlação entre porcentagem de emergência de plântulas, estimativa de germinação pelo teste de tetrazólio, teor de umidade e condutividade elétrica de sementes de seringueira (Hevea brasiliensis L.) avaliadas após armazenamento.

\begin{tabular}{lcccc}
\hline & Germinação & Tetrazólio & Umidade & Condutividade Elétrica \\
\hline Emergência de plântulas & 1 & $0,6084^{*}$ & $-0,5389^{*}$ & $-0,6320^{* *}$ \\
Tetrazólio & & 1 & $-0,3197^{\mathrm{ns}}$ & $-0,6886^{* *}$ \\
Umidade & & 1 & $0,0956^{\mathrm{ns}}$ \\
Condutividade Elétrica & & & & 1 \\
\hline
\end{tabular}

* e**: significativo a 1 e $5 \%$ de probabilidade, respectivamente.

Constatou-se que a análise de regressão da (Figura 1). O R2 de 0,9995 indica que o modelo porcentagem de emergência de plântulas de quadrático adequou-se bem às médias de seringueira em função do tempo de porcentagem de emergência de plântulas em armazenamento gerou modelo quadrático com função do tempo de armazenamento. valores de R2 significativos a 5\% de probabilidade

Figura 1 - Porcentagem de emergência de plântulas de seringueira (Hevea brasiliensis L.) ao longo do armazenamento.

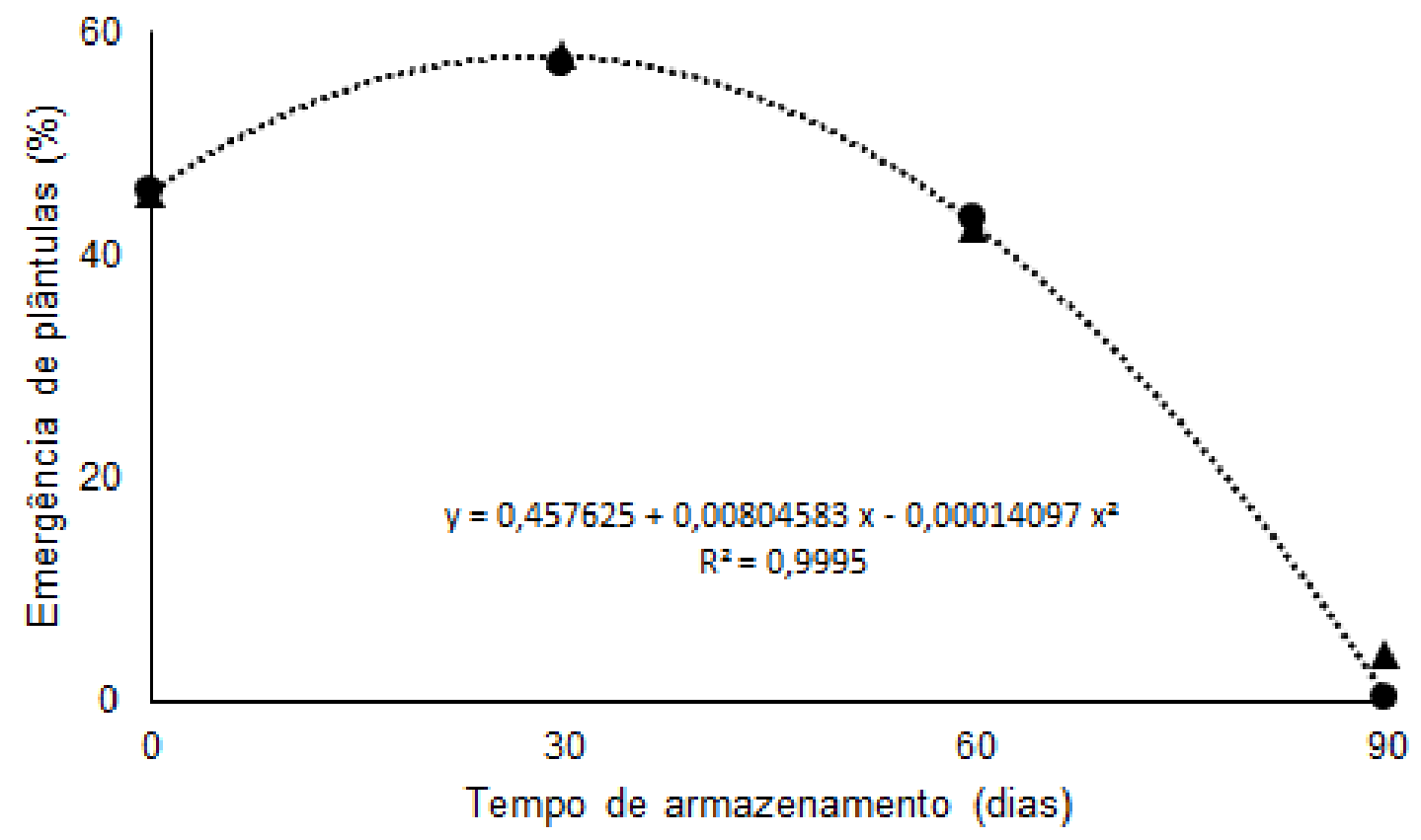

As porcentagens de emergência de manutenção da taxa de emergência com pouca plântulas de seringueira foram sempre inferiores a $60 \%$ possivelmente devido ao método de coleta das sementes, que ocorreu sem a pré-limpeza do local, o que colaborou para a presença de sementes que não haviam caído somente no dia da coleta. $\mathrm{O}$ método de armazenamento utilizado possibilitou a conservação das sementes até os 60 dias, com variação entre a testemunha, o primeiro e segundo teste. Após 60 dias, as sementes já demonstravam uma leve queda na porcentagem de emergência de plântulas, situação também relatada por Bonome et al. (2009). O armazenamento a temperatura ambiente ajudou a controlar o metabolismo da semente e a manter a taxa de emergência de 
plântulas com pouca variação em relação a testemunha.

No início do experimento as sementes começaram a germinar após o $16^{\circ}$ dia de plantio. Depois de 90 dias de armazenamento, foram necessários 20 dias para o início da emergência de plântulas. Haviam sementes iniciando a germinação até o $30^{\circ}$ dia de plantio, resultados semelhantes aos de Garcia e Vieira (1994), os quais demonstraram que a semente armazenada em temperatura ambiente levava cerca de 30 dias para germinar. Quanto ao início da germinação, e o desenvolvimento da raiz, com 12 dias de plantio, mexendo sob a areia onde as sementes estavam plantadas, era possível encontrar algumas sementes em preparação para a emergência.
Obteve-se modelo linear do efeito do tempo de armazenamento no teor de umidade das sementes de seringueira após a realização da análise de regressão. O R2 encontrado foi significativo a 5\% de probabilidade (Figura 2). Assim, a equação obtida foi adequada para explicar o efeito do tempo de armazenamento no teor de umidade das sementes. O coeficiente referente ao tempo de armazenamento revela que, a cada dia de armazenamento, o teor de umidade da semente de seringueira aumentará 0,07\%. O R2 de 0,81 indica que o modelo linear ajusta-bem aos teores de umidade das sementes obtidas em função do tempo de armazenamento.

Figura 2 - Teor de umidade de sementes de seringueira (Hevea brasiliensis L.) ao longo do armazenamento.

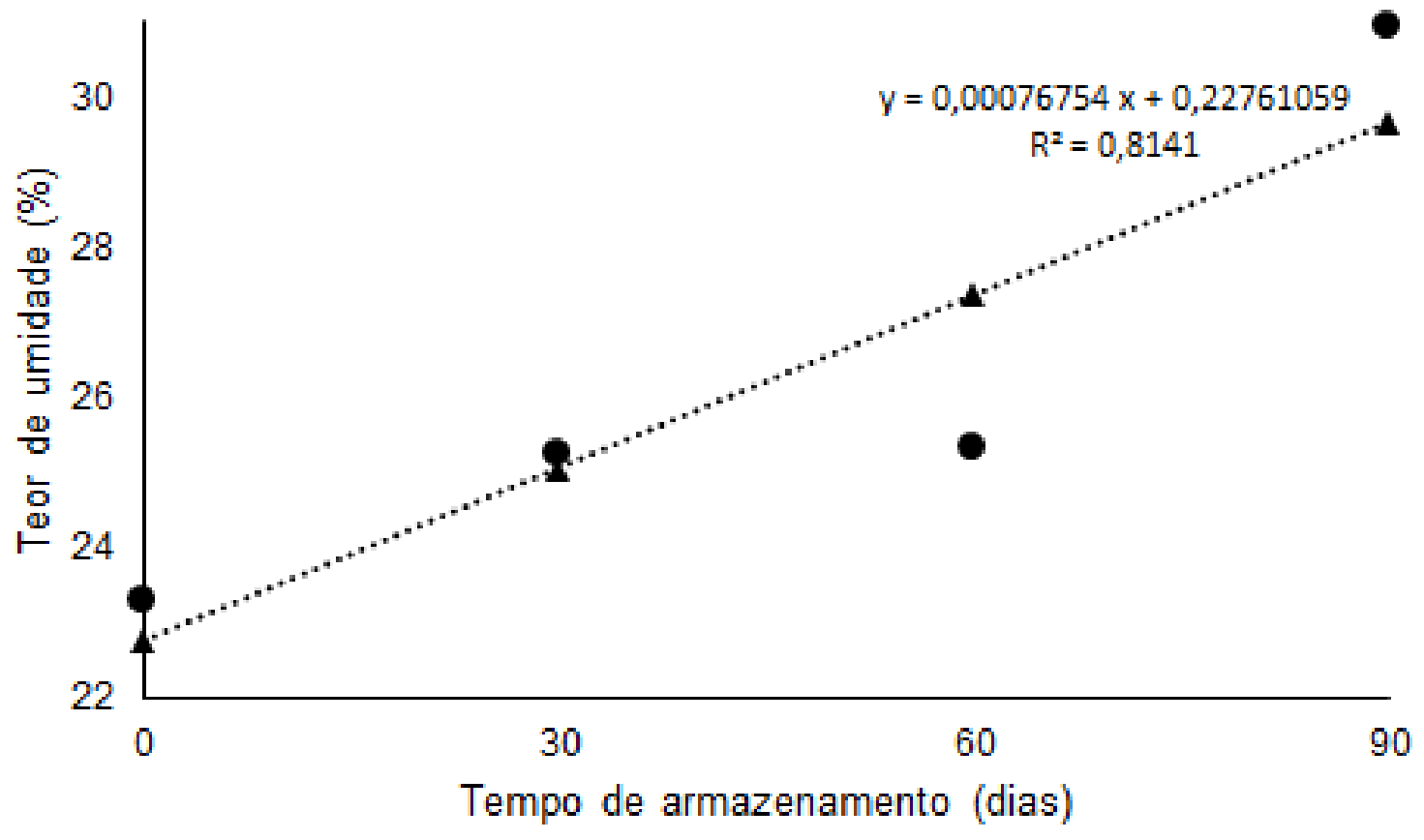

A umidade das sementes apresentou pouca variação nos primeiros 30 dias de armazenamento (Figura 2). Observou-se que os sacos plásticos onde as sementes estavam armazenadas permaneceram secos nesse período. Entre os dias 30 e 60 houve leve umidificação das pontas dos 
sacos e, visivelmente, em algumas sementes, o que ocasionou aumento de umidade. Segundo Bonome et al. (2009), a semente necessita possuir teor de umidade de 30\% para germinar, porém, desde o início do plantio constatou-se, na testemunha, que já haviam sementes com nível de umidade abaixo do mencionado na literatura (médias de 25\%). Acredita-se que o método de coleta das sementes utilizado neste trabalho também colaborou para que as sementes da testemunha apresentassem teor de umidade abaixo do requerido.

O aumento do teor de umidade das sementes de seringueira ao longo do tempo de armazenamento provocou interferência na germinação, o que está relacionado ao ambiente propício ao desenvolvimento de fungos (PEREIRA, 1980). Este mesmo autor observou que sementes de seringueira armazenadas em sacos plásticos meio cheios não mantiveram a taxa de emergência de plântulas superior a 50\% após 90 dias em relação a testemunha. Neste trabalho, foi possível observar que a maior taxa de emergência de plântulas ocorreu com umidade na faixa de $25 \%$, o que difere dos resultados encontrados por Garcia e Vieira (1994), os quais afirmam que teores de umidade inferiores a 30\% ocasionaram queda no índice de germinação. No entanto, também foi observado que valores de umidade de $25 \%$ proporcionaram menor atividade de fungos e a taxa de emergência de plântulas manteve-se comparada a testemunha.

Observou-se também que os sacos plásticos não apresentaram alta densidade de gotículas de água com evidência de sinais de alta umidade. A alta umidade observada era relativa somente à presença dos fungos nas sementes.
Bonome et al. (2009) também relataram aumento da atividade de fungos nas sementes, principalmente nas sementes não tratadas com fungicidas, pois o fungicida causa fitotoxidade.

Visualmente, foi possível observar a existência de muitas sementes com maior umidade e outras mais secas, contendo alta atividade de fungos e outras com menor atividade. Contudo, apesar de muitas sementes estarem com boa aparência a olho nu, essa análise visual não foi considerada precisa, pois, grande parte das sementes que estavam visivelmente boas, quando submetidas ao teste de tetrazólio, demonstraram que este tipo de avaliação não é suficiente para avaliar o potencial germinativo das sementes, o que difere de Oliveira (2012).

Com 90 dias, algumas pouquíssimas sementes encontravam-se ocas, ou com seu interior completamente dissolvido. Acredita-se que este fato ocorreu pela atividade de fungos, já que a atividade de insetos foi descartada porque os sacos estavam selados para aberturas de insetos maiores e em nenhuma das sementes foi constatada a presença de insetos.

\section{CONCLUSÕES}

O teste de tetrazólio pode ser utilizado em substituição ao teste de emergência de plântulas em canteiro para sementes de seringueira.

Os testes de tetrazólio, umidade, e condutividade elétrica são testes eficientes e rápidos na execução.

As sementes de seringueira podem ser conservadas viáveis em temperatura ambiente por até 2 meses. 
A taxa de umidade de aproximadamente $25 \%$ foi a mais eficiente para a conservação das sementes de seringueira.

\section{REFERÊNCIAS}

ABRABOR. Borracha natural: uma oportunidade. São José Do Rio Preto, São Paulo, 2014. 3p.

BARBEDO, C. J.; CENTENO, D. C. C.; RIBEIRO, R. C. L. F. Do recalcitrant seeds really exist? Hoehnea, São Paulo, v. 40, n. 4, p. 583-593, 2013.

BONOME, L. T. S.; OLIVEIRA, L. E. M. de; GRACIANO, M. H. P.; MATTOS, J. O. S.; MESQUITA, A. C. Influência do tratamento fungicida e da temperatura sobre a qualidade fisiológica de sementes de seringueira durante o armazenamento. Agrarian, Lavras, v. 2, n.5, p. 97-112, 2009.

BONOME, L. T. S. Alterações Fisiológicas Bioquímicas e Moleculares de sementes de seringueira [Hevea Brasiliensis (Willd. Ex Adr De Juss.) Müell.-Arg.] durante o armazenamento. 2006. $136 \mathrm{f}$. Tese (Doutorado em Fisiologia Vegetal), Pós-graduação Fisiologia Vegetal. Lavras, Minas Gerais, 2006.

D’AGOSTINI, S.; BACILIERI, S.; VITIELLO, N.; HOJO, H.; BILYNSKYJ, M.C.V.; BATISTA FILHO, A.; REBOUÇAS, M. M. Ciclo econômico da borracha - seringueira Hevea brasiliensis (HBK) M. Arg. Instituto Biológico, Centro de Comunicação e Transferência do Conhecimento, Museu/Centro de Memória, São Paulo, v. 9, n.1, p.6-14, 2013.

FURTADO E. L.; CUNHA A. R. da; ALVARES C. A.; BEVENUTO J. A. B.; PASSOS J. R. Ocorrência de epidemia do mal das folhas em regiões de "escape" do Brasil. Arquivo do Instituto Biológico, São Paulo, v. 82, n. único, p. 1-6, 2015.

GARCIA, A.; VIEIRA, R. D. Germinação armazenamento e tratamento fungicida de sementes de seringueira (Hevea brasiliensis Muell. Arg.). Revista brasileira de sementes, Londrina, v. 16, n. 2, p. 128-133, 1994.

GASPAR-OLIVEIRA C. M.; MARTINS C. C.; NAKAGAWA, J. Concentração da solução de tetrazólio e período de coloração do teste para sementes de mamoneira. Revista Brasileira de Sementes, Londrina, v. 31, n. 3, p.038-047, 2009.

NOGUEIRA R. F.; CORDEIRO S. A.; LEITE A. M. P.; BINOTI M. L. M. S. da; Mercado de borracha natural e viabilidade econômica do cultivo da seringueira no Brasil. Nativa Pesquisas Agrárias e Ambientais, Sinop, v. 03, n. 02, p. 143-149, 2015.

OLIVEIRA, A. P. Determinação da viabilidade e do vigor em sementes de seringueira. 2012. 61 f. Dissertação (Mestrado em Agronomia), Pós-Graduação em Agronomia, Universidade Federal de Goiás, Goiânia, Goiás. 2012

PEREIRA, J. P. Conservação da viabilidade do poder germinativo da semente de seringueira. Pesquisa agropecuária brasileira, Brasília, v. 15, n. 2, p. 237-244, 1980.

PICHELLI, K. Produtividade de seringais em Goiás é maior que a média mundial. 2016

Disponível em: $<$ https://www.embrapa.br/busca-denoticias//noticia/11705438/produtividade-deseringais-em-goias-e-maior-que-a-mediamundial >. Acesso em: 15 fev. 2019.

VIEIRA，R. D.; BERGAMASCHI, M. C. M.; MINOHARA, L. Qualidade fisiológica de sementes de seringueira (Hevea brasiliensis Muell. Arg.), tratadas com benlate durante o armazenamento. Scientia Agricola, Piracicaba, v. 54, n. 1, p. 151-157, 1995.

RAS. Regras para análise de sementes - Brasília 2009. Ministério da Agricultura, Pecuária e Abastecimento, p.147-323. 399p. 
SOUZA, G. A. Alterações fisiológicas e bioquímicas em sementes de seringueira [Hevea brasiliensis (Willd. Ex Adr. De Juss.) MÜELL.-ARG.] durante o desenvolvimento e o armazenamento. 2014. 135 f. Tese (Doutorado em Scientiae)Pós-Graduação em Fisiologia Vegetal. Universidade Federal de Viçosa, Viçosa, Minas Gerais, 2014.

SILVA, S. E. L.; OZANAN, F. Cultura da Seringueira - Bases para implantação de sementeira, viveiro, jardim clonal e plantio definitivo. Embrapa - Centro de Pesquisa Agroflorestal da Amazônia. 20p. Manaus, Amazonas, 1989.

TOLEDO, M. Crise na borracha leva a demissões e corte de árvores no interior de SP: Excesso de produção mundial derruba preço do látex e incentiva substituição da cultura. 2018. Disponível em: $<$ https://www1.folha.uol.com.br/mercado /2018/06/crise-na-borracha-leva-ademissoes-e-corte-de-arvores-no-interiorde-sp.shtml>. Acesso em: 20 fev. 2019.

VIDIGAL, D. S.; LIMA, J. S.; BHERING, M. C.; DIAS, D. C. F. S. Teste de condutividade elétrica para semente de pimenta. Revista Brasileira de Sementes, Londrina, v. 30, n. 1, p.168-174, 2008.

WETZEL, M. M. V. S.; CÍCERO, S. M.; FERREIRA, B. C. S. Aplicação do teste de tetrazólio em sementes de seringueira. Revista Brasileira de Sementes, Londrina, v. 14, n. 1, p. 83-88, 1992. 